\title{
Analysis on Mechanism of Vegetation Slope Protection based on Security Perspective
}

\author{
Du Guangqian and Wang Shijie \\ Agricultural University of Hebei, 071001, China \\ 476118298@qq.com
}

\begin{abstract}
Vegetation slope protection is a kind of slope protection technology in engineering, but research on its reinforcement mechanism lags behind engineering practice. In this paper, the mechanical model of the interaction between vegetation root and rock is established, and the mechanical anchoring mechanism is analyzed. The results show that the reinforcement effect of plant roots on rock and soil reinforcement can be regarded as a three-dimensional effect. The reinforcement effect of vertical root can be simplified as axial effect, and the lateral principal root is friction reinforcement effect. And rock friction resistance to balance the excess slope soil thrust.
\end{abstract}

Keywords: Ecological slope protections, Plant root system, Finite element analysis

\section{Introduction}

Ecological slope protections as an engineering technology, many countries has studied it's reinforcement mechanism and technology applications. Overall, Japan is a leader in the study of ecological slope protection engineering technology, the development of hydroseeding method, fiber green chemical method of soil, vegetation, porous concrete and other construction method has been widely used in ecological highway slope protection works; Europe and America around the country's main highway slope and embankment revetment to prevent rainwater from erosion and development of cuttings, layering, hedges, hydraulic gushing, three-dimensional grass slope ecological protection technology.

China in the early 1990s with Japan for the first time in the Loess Plateau were studied hydroseeding, after a decade of development, the technology has been widely used in highway warm and humid areas of South China, Central China, East China, railways and dams ecological Protection Engineering, then, China imported geonet slope Stabilization technology, and the development of three-dimensional vegetation net, geogrid, Geo network, Geocell and other ecological slope protection technology, slope protection highway, railway, water conservancy projects in the have access to extension application. Research on reinforcement mechanism inferior slope and rock slope of ecology and engineering applications to carry out less accumulated experience relatively plaque lack. Therefore, this paper start from the microscopic mechanical model of vegetation roots rock interaction to explain the mechanism of ecological slope protection, and look forward to an accumulation of some ecological protection experiences[1].

\section{Herb Roots- rock Interaction Mechanism}

Since the density of plant roots in the soil from the surface down decreases gradually thin, in the range of roots twine, slope rock mass can be seen as the root of a composite soil and roots from the soil composition. Herb root as the role of reinforcement fibers, as the number per unit volume in the roots, rock and soil shear capacity also will increase, so can the principle of reinforced soil slope rock mass 
stress state analysis, namely, the distribution of the roots of rock and soil reinforcement fibers treated as distributions, and for three-dimensional reinforcement. This reinforced the rock layers provide additional "cohesion", which on the one hand the shear strength of the original rock mass goes up because of the distance, and on the other hand limits the lateral expansion of leaving the soil increases to. In the lateral stress unchanged the maximum shear stress is reduced, so that the carrying capacity of these two effects the slope of rock and soil improvement ${ }^{[2]}$.

Front part qualitatively analyzed Mohr Have reinforced soil by plant roots at failure. The following analyze the reinforcement effect by establishing a quantitative mechanics herb root-soil interaction model of plant roots.

Figure 1 is a single herb mechanical model of reinforced soil, Fig 1 (a) the shear zone extending direction of the root and soil orthogonal case, Figure 1 (b) indicate the direction of extension of the root and soil oblique shear zone scenario.

According to Figure 1 shows that, when orthogonal

$$
\tau_{R 1}=\frac{T}{\alpha} \sin \theta+\frac{T}{\alpha} \cos \theta \tan \varphi
$$

(1)

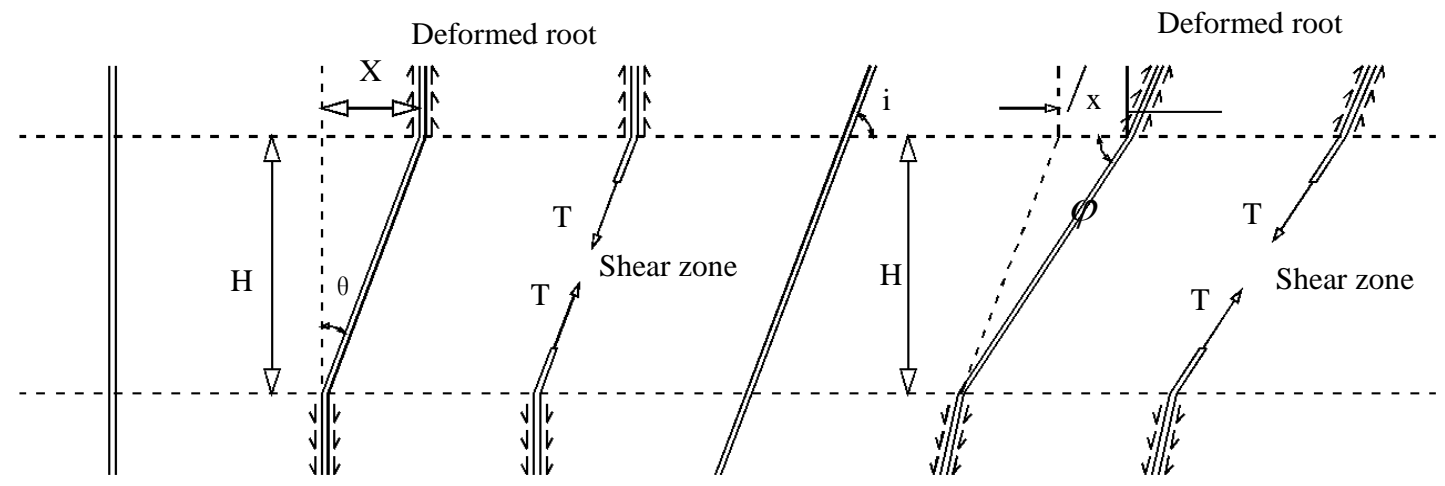

Figure 1. Rock Roots Mechanical Model Interaction

(3)

When skew,

$$
\begin{aligned}
& \tau_{R 2}=\frac{T}{\alpha} \sin \left(90^{0}-\varphi\right)+\frac{T}{\alpha} \cos \left(90^{\circ}-\varphi\right) \tan \varphi \\
& \varphi=\tan ^{-1}\left[\frac{1}{k+\left(\tan ^{-1} i\right)^{-1}}\right]
\end{aligned}
$$

Where: is due to the reinforcement effect of the increased root soil shear strength, $\mathrm{T}$ is a single tensile strength $(\mathrm{N})$, is single soil area, is shear angle degeneration, is the internal friction angle of the soil, .i is the extending direction of the initial shear plane angle, $\mathrm{k}$ is the shear deformation ratio, $\mathrm{k}=\mathrm{x} / \mathrm{H}, \mathrm{H}$ is the thickness of the shear zone ${ }^{[3]}$.

If the soil in the area of in vivo A total of $\mathrm{n}$ root, root pull stress are , .., shear deformation angles are ,..., and the angle between the direction of extension of the initial shear surface roots are ,..., shear deformation ratios of ,..., then the formula (1), (2) and(3) are respectively, 
$\tau_{R 1}=\frac{\sum_{j=1}^{n} T_{j} \sin \theta_{j}}{A}+\frac{\sum_{j=1}^{n} T_{j} \cos \theta_{j}}{A} \tan \varphi$

(4)

$\tau_{R 2}=\frac{\sum_{j=1}^{n} T_{\mathrm{j}} \sin \left(90^{\circ}-\varphi_{j}\right)}{A}+\frac{\sum_{j=1}^{n} T_{j} \cos \left(90^{\circ}-\varphi_{j}\right)}{A} \tan \varphi$

(5)

$\varphi_{j}=\tan ^{-1}\left[\frac{1}{k_{j}+\tan ^{-1} i_{j}}\right](j=1,2, \ldots . n)$

(6)

If there are $\mathrm{n}$ roots soil body area $\mathrm{A}$, in which are $\mathrm{m}$ orthogonal roots, $\mathrm{n}-\mathrm{m}$ bias roots, root stress are ,.., orthogonal shear deformation angles are , .., the angle between the initial direction of the shear plane extending skew roots are , ..., then the shear deformation are by the shear strength of roots into soil reinforcement effect become

$\tau_{R}=\tau_{R 1}+\tau_{R 2}$

(7)

From the above equation, determination the size of need $m, n,$, and. Among them, through the direct shear test, parameters can be obtained, the parameter $\mathrm{m}, \mathrm{n}$ and, can be obtained by intercepting a longitudinal section containing the roots , and by the wild root obtained direct shear tests. For the parameter,because the root of most herbs withdrawn from the soil, when it are pulled off, we can see the root tensile strength less than roots and soil Mount.

Rub force, therefore $\mathrm{T}$, available from the root of the laboratory to determine the tensile test.

From the above analysis, by the herb roots reinforced, the soil shear strength can be written as

$\tau=c+\sigma \tan \varphi+\tau_{R}=\left[\mathrm{c}+\frac{\sum_{j=1}^{n} T_{j} \sin \theta_{j}}{A}\right]+\left[\sigma+\frac{\sum_{j=1}^{n} T_{j} \cos \theta_{j}}{A}+\frac{\sum_{j=m+1}^{n} T_{j} \cos \left(90^{0}-\varphi_{j}\right)}{A}\right] \tan \varphi$

\section{Experimental Study on Strengthening the Role of Vegetation Root}

In order to study the effect of root growth herb in slope surface, we take undisturbed soil from Zhang Shi Expressway two work sites, respectively completed the natural soil density, moisture content, different amount of soil containing roots shear strength test.

The soil density, water content similarly, the comparison of no root soil shear strength are shown in Figure 2.

Figure 2 shows, there is the shear strength of the root surface soil slope was significantly greater than the slope without the shear strength of the root surface soil. The test results demonstrated strong roots on slope surface vegetation significantly reinforcing effect.

Strengthening the role of plant roots on slope surface soil can be used to explain the principles of reinforced soil (Figure 3): root causes soil vegetation within the scope of the extension of secondary roots to form a whole. Root density distribution in the soil, white surface downwards gradually reduced, gradually thin. According to various roots dig deep surface inspection deepest $0.6-0.8 \mathrm{~m}$. The actual range in the roots twine, slope soil is a composite material consisting of the soil and roots. 
Therefore, when considering Slope Shallow soil strength, should be soil - root strength of the composite material as the basis, namely the distribution of the soil is considered grassroots reinforced material distribution, and is a multidimensional ribs, which provide additional reinforcement for the soil " cohesion", and it's size is related to the grass-roots density, intensity and nature of the soil particles. It makes the shear strength of the original soil line goes up a distance, which makes it the root of soil shear strength is greatly increased ${ }^{[4]}$.

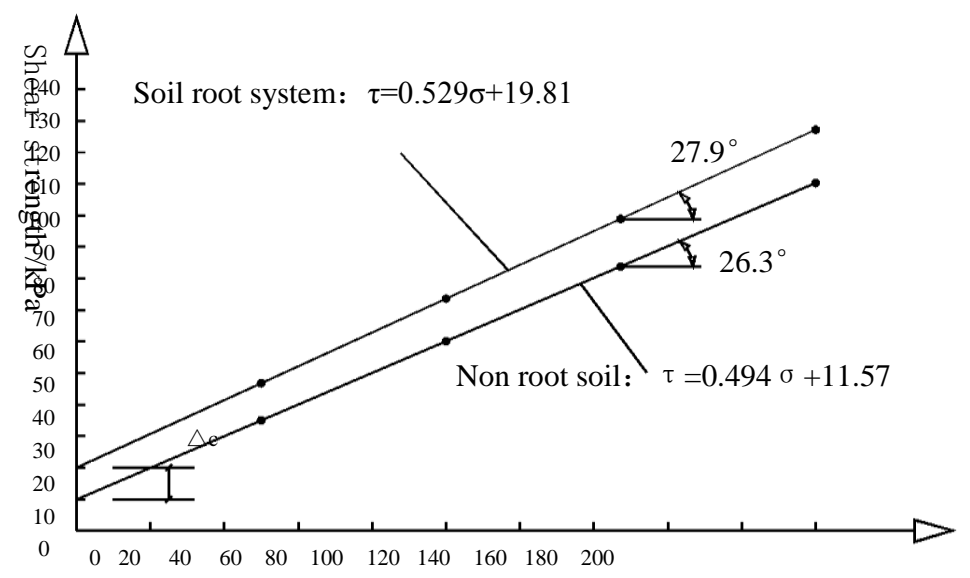

Figure 2. Comparison of Shear Strength for the Soil with and without Roots Respectively

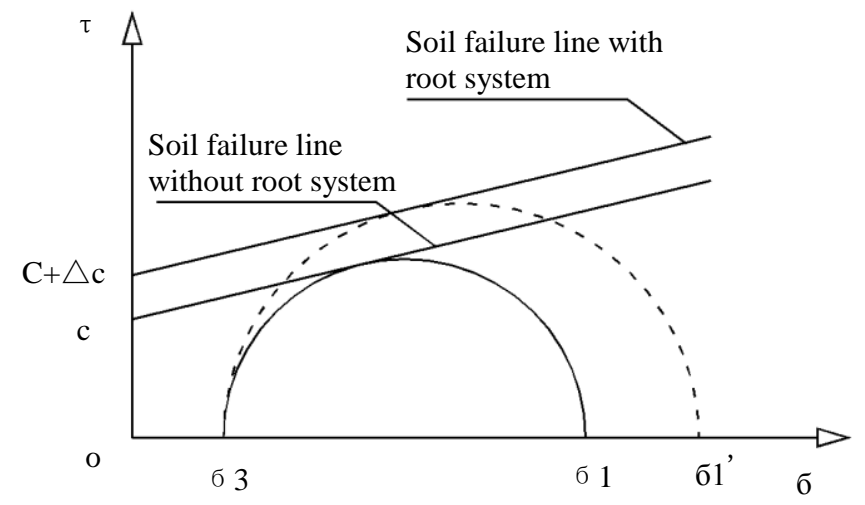

Figure 3. Mechanical Improvement of Roots to the Soil

Shear strength is the internal friction and the cohesive force, the sum of the roots of the vegetation, especially the root in the soil around and growth, penetration depth, intertwined, and make the soil particles together tightly connection, form a solid empty asked as a whole.

Within 10 to $50 \mathrm{~cm}$ in deeply, the slope is composed of soil and plant roots composites, the properties of reinforced soil is similar. According to the principle of reinforced soil, add reinforced soil to improve strength of soil mass. Of plant roots and soil "reinforced", its strength is also increased. His body shear strength can better reflect its stability ${ }^{[5]}$.

Should be, due to the vegetation root the intertwining, on-site sampling is very difficult (figure 4), and to make test sample, will be for some root resection, actually has a root of the reinforced soil cohesive force value is much larger than the test results, the reinforcement of the slope surface is very beneficial. 
For the study of water on the green protective layer shear strength, the effect of experiment under the different moisture content tested green protective layer, shear strength and test data are shown in table 1.

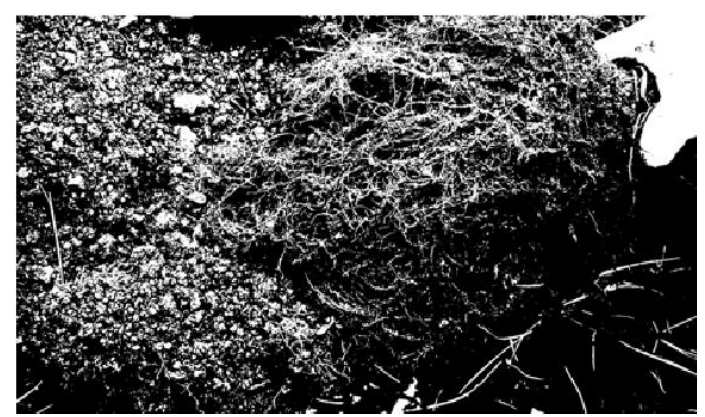

Figure 4. Plant Root Net

Table 1. Shear Strength of the Greening Protecting Layer under Different Average Water Contents

\begin{tabular}{cccc}
\hline $\begin{array}{c}\text { Experimental } \\
\text { group }\end{array}$ & $\begin{array}{c}\text { Average moisture } \\
\text { content/\% }\end{array}$ & $\begin{array}{c}\text { Shear stress } \\
/\left(10^{-2} \mathrm{kPa}\right)\end{array}$ & $\begin{array}{c}\text { Vertical load } \\
/ \mathrm{kPa}\end{array}$ \\
\hline 1 & 23.526 & 21.42 & 50 \\
2 & 16.006 & 40.46 & 50 \\
3 & 13.660 & 40.46 & 50 \\
4 & 17.454 & 35.70 & 50 \\
5 & 9.209 & 47.60 & 50 \\
6 & 13.848 & 38.08 & 50 \\
\hline
\end{tabular}

The average moisture content and protective layer shear strength curve is shown in figure 3.

The figure 3 shows that the soil's shear stress decreases gradually along with the increase of moisture content, and the quadratic parabola form of downwards. Too little soil moisture will directly affect the survival of vegetation. When too much water also affects soil root growth and root functions. First of all, when the soil moisture content is higher, experience hypoxia resulting in a decline in the root respiration rate and soil anaerobic respiration can also lead to the root of the accumulation of toxic products such as ethanol, led to the deaths of root tip, on the slope surface soil ability are significantly reduced. Second, at high soil moisture, soil particles and greatly reduce the friction root asked, prompting a sharp drop in the shearing strength of the herbaceous plant roots.

Rainfall is one of the important factors of the slope instability, so when factors such as rainfall led to increased soil moisture, often occur slope slide. Green barriers, through the absorption and transpiration of vegetation slope body moisture, reduce the pore water pressure of soil, increase soil cohesive force, improve the soil shear strength, is conducive to the stability of the slope body. Of course, when the moisture content is low to a certain extent, the shear strength of soil will reach a constant value, not increases indefinitely.

forward to an accumulation of some ecological protection experiences. 


\section{Green Protective Layer Deformation Finite Element Analysis}

There is a certain thickness of the soil slope surface, is a prerequisite for green slope protection. The traditional limit equilibrium method in slope stability analysis of surface soil, can't analyze green slope protection layer under the action of gravity deformation condition. This part uses the general finite element program to simulate the deformation of slope surface soil in order to determine the slope surface deformation of soil mass under the action of gravity and the relationship between the slope height, slope ${ }^{[6]}$. Mechanics parameter values are shown in table2.

In order to study the slope green protective layer in the presence of root system under the condition of deformation and the relationship between slope height, slope ratio. This article uses the finite element method to analyze the deformation of slope green protection layer, calculate what model shown in figure 5, and finite element calculation model is shown in figure 6.

Respectively in the calculation of deformation of bottom, middle and upper 3 point comparison found that presence of plant root system ${ }^{[7]}$, the biggest deformation points now central slope protection layer (" 2 "point in figure 9) protective layer for the destruction of the main" ballooning "in the middle of slope failure. Different slope height and slope ratio of green protective layer $(25 \mathrm{~cm}$ thick) deformation are shown in table 3 .

The table 3 shows that there are deformation of root growth of vegetation slope protection layer is smaller than without root deformation of slope protection layer ${ }^{[8]}$.

\section{Table 2 Physico-mechanical Parameters of the Greening Protection} Layer

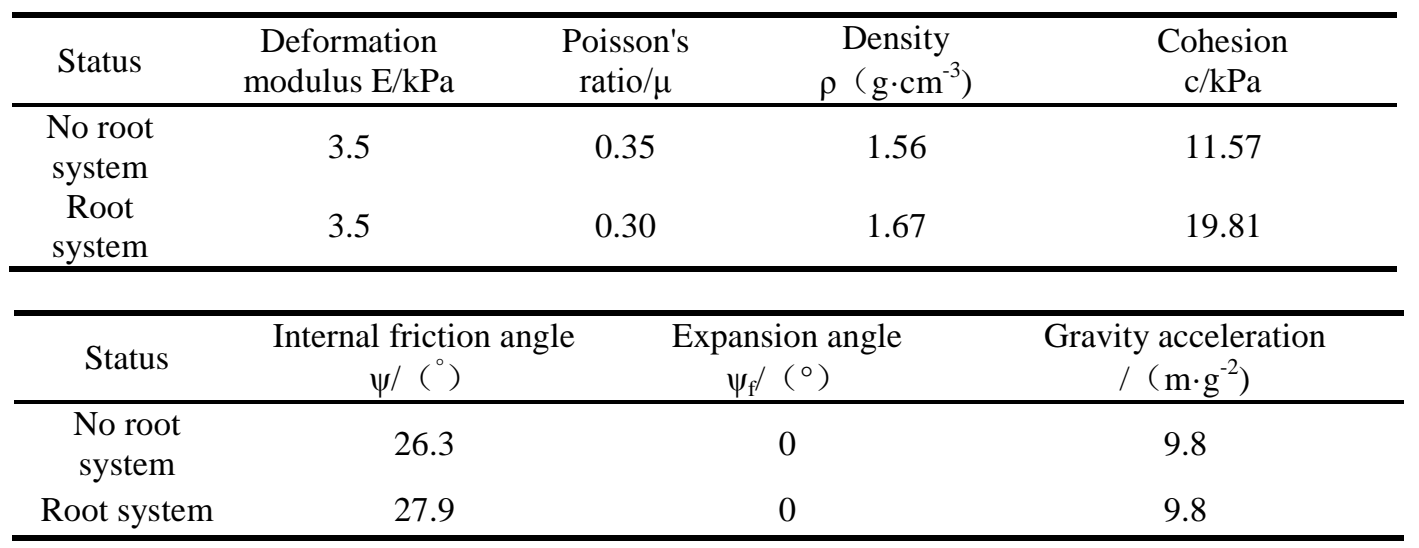

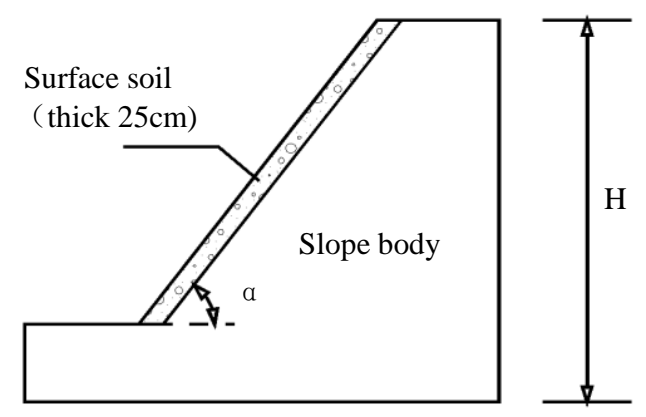

Figure 5. Geometry Model of Greening Protection Layer 
In combination with YuHuaiXian worksite, in this paper, the protective layer of $10 \mathrm{~cm}$ thick, with barbed wire protection when green protective layer deformation finite element analysis.

The results are shown in table 4

Contrast table 3, 4, with the decrease of the thickness of protection layer, green protective layer is less deformation values. When the protective layer of $10 \mathrm{~cm}$ thick, with barbed wire protection, green protective layer in the slope ratio is 1:0.5, the maximum when the slope is $12 \mathrm{~m}$ high slope deformation points (" 3 "position shown in figure 9) deformation is $9.26 \mathrm{~mm}$. Such a case, the main factors that affect the growth of vegetation for slope green protective layer are water supply and maintain. Field investigation found that green protective layer $10 \mathrm{~cm}$ thick, with barbed wire protection slope surface destruction mainly is the vegetation growth in the early rain wash $^{[9]}$.

Table 3 Deformation of Greening Protecting Layer with Thickness of $10 \mathrm{~cm}$ for Different Slope Heights and Slope Ratios

\begin{tabular}{lccc}
\hline Slope & $\begin{array}{c}\text { High slope } \\
8 \mathrm{~m}\end{array}$ & $\begin{array}{c}\text { High slope } \\
10 \mathrm{~m}\end{array}$ & $\begin{array}{c}\text { High slope } \\
12 \mathrm{~m}\end{array}$ \\
\hline $\mathrm{F}_{1: 1}$ & -1.68 & -3.74 & -4.01 \\
$1: 0.75$ & -2.00 & -4.10 & -8.80 \\
$1: 0.5$ & -7.03 & -7.51 & -9.26 \\
\hline
\end{tabular}

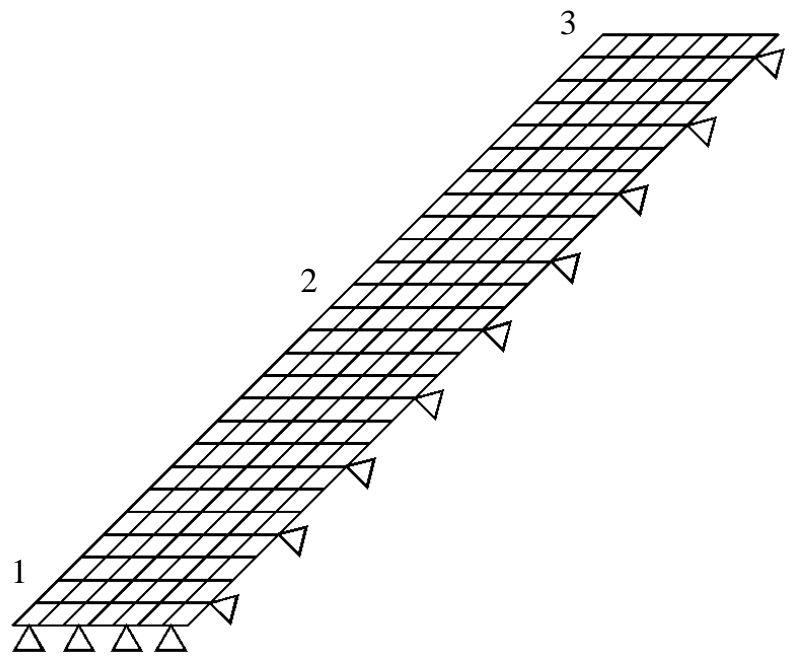

Figure 6. Finite Element Model of Greening Protection Layer 


\section{Table 4. Deformation of Greening Protecting Layer with Thickness of $25 \mathrm{~cm}$ for Different Slope Heights and Slope Ratios}

$\mathrm{mm}$

\begin{tabular}{ccccccc}
\hline \multirow{2}{*}{ Slope } & \multicolumn{2}{c}{ High slope } & \multicolumn{2}{c}{ High slope } & \multicolumn{2}{c}{ High slope } \\
& \multicolumn{2}{c}{$5 \mathrm{~m}$} & \multicolumn{2}{c}{$10 \mathrm{~m}$} \\
\cline { 2 - 7 } & $\begin{array}{c}\text { No root } \\
\text { system }\end{array}$ & $\begin{array}{c}\text { Root } \\
\text { system }\end{array}$ & $\begin{array}{c}\text { No root } \\
\text { system }\end{array}$ & $\begin{array}{c}\text { Root } \\
\text { system }\end{array}$ & $\begin{array}{c}\text { No root } \\
\text { system }\end{array}$ & \multirow{2}{*}{ Root system } \\
\hline $1: 1$ & -15.5 & -14.60 & -24.50 & -16.30 & -27.80 & -20.90 \\
$1: 0.75$ & -20.2 & -15.90 & -24.80 & -17.40 & -27.60 & -21.11 \\
$1: 0.5$ & -23.0 & -19.90 & -27.90 & -19.30 & -32.60 & -23.40 \\
\hline
\end{tabular}

\section{Conclusion}

According to above analysis can draw the following conclusion:

(1) slope surface growth of vegetation roots can effectively improve slope surface soil shear strength.

(2) the deformation of slope green protection layer was mainly affected by the following aspects: with the increase of the upper soil pressure, shear deformation is generated in soil makes the soil in the slope direction ( $\mathrm{x}$ direction) displacement increases gradually, if the heap to the deformation of the soil on slope surface, is on the soil below the larger pressure, make the distance under the slope soil also produces lateral deformation and failure.

(3) with root slope, the slope of its deformation is small, the influence of the high slope on its deformation. In engineering design of slope can be reduced for each level of the slope height, can effectively increase the stability of the protective layer.

(4) green protective layer thickness had a great influence on the deformation, when the green protection layer $10 \mathrm{~cm}$ thick, with barbed wire protection, protective layer deformation value is small, when the slope ratio of 1:0.5, and the slope is $12 \mathrm{~m}$ high , at the top X direction's maximum deformation is $9.26 \mathrm{~mm}$, protective layer can be stable, under the condition of the vegetation growth is the key to smoothly according to the protective layer can provide sufficient moisture.

It is important to note that in the early to green slope protection and vegetation root system network has not yet formed, the slope protection layer influenced by rainfall and so on, are mainly composed of erosion damage. So in the early to green slope protection should also be combined with other engineering protection measures to prevent the slope green protective layer at the beginning of the vegetation growth is not destroyed.

\section{References}

[1] Zhang Junyun, Zhou Depei, Li Shaocai,"Testing study on planting material for rock slope”, Chinese Journal of Rock Mechanics and Engineering, vol. 2, no. 20, (2001), pp. 239-242.

[2] Zhou Depei, Zhang Junyun. "Engineering Techniques for Slope Planting", China Communications Press, Beijing,(2003).

[3] Xie Mingshu, "A study on the soil mechanical role of tree roots in the stability of slopes", Journal of Soil and Water Conservation, vol. 4, no. 3, (2013), pp. 7-14.

[4] Xiao Henglin,Ma Qiang,Ye Jianjun,Wan Juan,Li Lihua,"Cement fiber backbone spray peat and ecological slope protection material formulation optimization and field test", Transactions of the Chinese Society of Agricultural Engineering, vol.2, no. 2, (2015), pp. 86-93.

[5] Xiao Henglin, Peng quan, Xiao Benlin, "Application and problem analysis of thick substrate spraying technology in slope protection of highway in Western Hubei Province",Journal of China \& Foreign Highway, vol.2, no. 3, (2011), pp. 96-100. 
[6] Wang hejun, Lee C F,"Brief mechanics analysis on bio engineering techniques for slope protection",Chinese Journal of Rock Mechanics and Engineering, vol. 2, no. 20, (2011), pp. 687-691.

[7] Zheng Yingren, Zhao Shangyi, "Deng Weidong. Numerical simulation on failure mechanism of rock slope by strength reduction FEM",Chinese Journal of Rock Mechanics and Engineering, vol. 3, no. 2, (2003), pp. 75-80.2003, 22(12):1943-1 952(in Chinese)

[8] Wang Yuanzhan,Huang Taikun,Huo Zhiliang,Yan Shuwang, "Construction monitoring and finite element analysis of large area slope excavation in soft soil area", Geotechnical Investigation \& Surveying, vol. 5, no. 11, (2015), pp. 67-72.

[9] ANSYS China,"Nonlinear analysis guide of ANSYS",China Communications Press (2003).

\section{Authors}

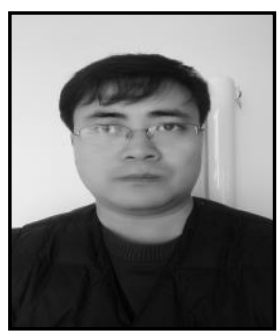

Du Guang-qian, Master, mainly engaged in geotechnical engineering, deep foundation pit engineering, the direction of slope stability was studied. 
International Journal of Security and Its Application Vol.11, No.1 (2017) 